\title{
Colony Forming Unit per Dish
}

National Cancer Institute

\section{Source}

National Cancer Institute. Colony Forming Unit per Dish. NCI Thesaurus. Code C74990.

A derived unit of viable cell concentration defined as the number of colony forming units

in one culture dish. 